\title{
Towards the Definition of Value-added Services for Citizens: a New Model for the Description of Public Administration Services
}

\author{
Marco Castelli, Marco Comerio, Marco Cremaschi \\ Dept. of Informatics, Systems and Communication (DISCo) \\ University of Milano - Bicocca, \\ Milan, Italy \\ \{marco.castelli,comerio,cremaschi\}@disco.unimib.it
}

\begin{abstract}
The Italian Public Administration (PA) consists in a wide set of local authorities (i.e., regions, provinces and municipalities) providing services to citizens, each with its own administrative autonomy. Actually, it often happens that Italian citizens have difficulties in discovering and using services that they need in the course of their lifes. Several Italian initiatives, such as the SMART (Services and Meta-services for smart e-Government) project, aim to simplify the interaction between Italian citizens and the PA trought the definition of value-added services. A value-added service (VAS) guides the citizen in the fruition of all services needed along a life event (e.g., the change of address). In this paper, we present a new version of the Italian Public Administration Service (IPAS) model defined for the description of PA services. We will show how the new model supports the description of concepts that simplifies the definition of VAS. A case study defined in the context of the SMART project will be presented.
\end{abstract}

\section{Indexing terms/Keywords}

Service models, service descriptions, value-added services, public administration services.

\section{Council for Innovative Research}

Peer Review Research Publishing System

Journal: International Journal of Management \& Information Technology

Vol.4, No.1

editor@cirworld.com

www.cirworld.com, member.cirworld.com 


\section{INTRODUCTION}

The Italian Public Administration (PA) is a set of administrations that includes more than 8,000 municipalities, 110 provinces and 20 regions, each with its own administrative autonomy and with the need to interact and integrate with each other. In addition, there are services that are provided by the central PA and other related agencies. Italian citizens have to be faced with this complexity and, often, they have difficulties in discovering and using services that they need in the course of their lifes.

Several Italian initiatives, such as the SMART (Services and Meta-services for smart e-Government) project, aim to simplify the interaction between Italian citizens and the PA. SMART is a project of industrial research and development that aims at producing digital services for both private and public sector, developing at the same time a formalisation of the activities in term of a methodology. This latter is intended to define a procedural path for the life-cycle of planning, design, production, sale, use, management and monitoring of services, from the point of view of three main actors: the planner (e.g. a Public Administration), the service provider (e.g. again a Public Administration or else a private broker), and the consumer of the service. The methodology proposed in SMART is the evolution of the eG4M methodology [1][2], formerly designed for strategic planning of e-Government services, thus extending it to a broader domain of application and target adopters.

The methodology is further based on Italian Public Aministration Services (IPAS) conceptual model, which extends the one proposed in [3], mainly focused on Government-to-Business (G2B) services. IPAS presents the novelty of modelling PA services from the view point of the value they have for consumers and providers. We intend to show that where Italian local authorities leave the citizen-users in a multitude of references to scope notes about pre-requisites for service applicability, IPAS model improves this condition by capturing the necessary background knowledge on administrative legislation in connection with service specifications, life events, and contexts of application.

In this paper, we will show how IPAS strongly supports the definition of value-added services (VAS) [3], i.e., services that maximise the value in use [4][13] for the citizen. A VAS simplifies the interaction with the PA guiding the citizen in the fruition of all services needed when a life event (e.g., the change of address of residence) occures. A case study defined in the context of the SMART project will be presented to demonstrate the support given by IPAS.

The paper is organized as follows. Section 2 describes the background in the definition of models for PA service description, underlying the open issues that justify our work. Section 3 presents the core concepts of the new version of the IPAS model and Section 4 proposes the above mentioned case study. Finally, Section 5 concludes the paper and presents our future work.

\section{BACKGROUND AND MOTIVATIONS}

In the last years, many projects focused on the definition of model for service description. For example, in the SmartCities project ${ }^{1}$, the European Local Government Service List (LGSL) has been produced as part of the Electronic Service Delivery (ESD)-toolkit website ${ }^{2}$, with the goal of define the semantics of public sector services. The general aim of that project is to create an innovation network between governments and academic partners leading to excellence in the domain of the development and uptake of e-services, setting a new baseline for e-service delivery in the whole North Sea region (England, Netherlands, Belgium, Germany, Scotland, Sweden, and Norway). Each country involved into the project is responsible to build and maintain its list of public services delivered to the citizens, and all of those services are interlinked to the services delivered by other countries.

The most important concepts used to model services in LGSL are: (i) services; (i) citizen needs; (iii) processes involved in service delivery; (iv) legal powers and duties under which the service is delivered; (v) channels through which a customer might access a service; (vi) metrics by which service delivery might be measured; and (vii) outcomes a service might improve.

In the academic literature, several models e.g., [3][10] have been proposed for service description. In [3] the IPAS model for the definition of semantic repositories for supporting G2B interactions is proposed. This model focuses on the identification of concepts oriented to G2B perspective. The top-level concepts of the model in [3] are: (i) services with their typologies, preconditions and effects; (ii) processes associated with services; (iii) actors involved in the service ecosystem; (iv) value of the services; (v) life events associated with services; (vi) the territory covered by the services and (vii) the resources needed by the services.

In [10] the eGora* conceptual model has been built to align the concept of service in service science and service oriented computing. The eGora* model is defined around the following first-level concepts: (i) services with their specialization in abstract, concrete, composite, atomic, aggregate, internal and external services; (ii) processes associated with services; (iii) actors involved in service provision and consumption; (iv) value of the services distinguished between public value and economic value; ( $v$ goals satisfied (all or in part) by executing the services and (vi) contracts that describes functional and non-functional properties of services.

From the analysis and comparison of the model used to define the LGSL and the ones in [3] [10] the following open issues

\footnotetext{
1 http://www.smartcities.info/aim

${ }^{2}$ http://www.esd.org.uk/esdtoolkit/
} 
emerge:

- $\quad$ the models do not permit a comprehensive characterization of the service value that, according to [13][11], can be of three different types: the social value, the exchange value and the value in use;

- the description of contractual terms, that regulate the service delivery, is limited to qualities of service (e.g., response time of the service) and business aspects (e.g., service price);

- $\quad$ services cannot be cathegorized according to the thematic area they cover (i.e., their context of application);

- there is not support for the description of user segmentation;

- $\quad$ there is not support for the description of user preferences.

The new version of the IPAS model described in the next section is proposed as a solution to these open issues.

\section{THE IPAS MODEL}

The entity around which the IPAS model is built is service. Services can be defined "as processes that consist of a set of activities which take place in interactions between a customer and people, goods and other physical resources, systems and/or infrastructures representing the service provider and possibly involving other customers, which aim at solving customers' problems" [5].

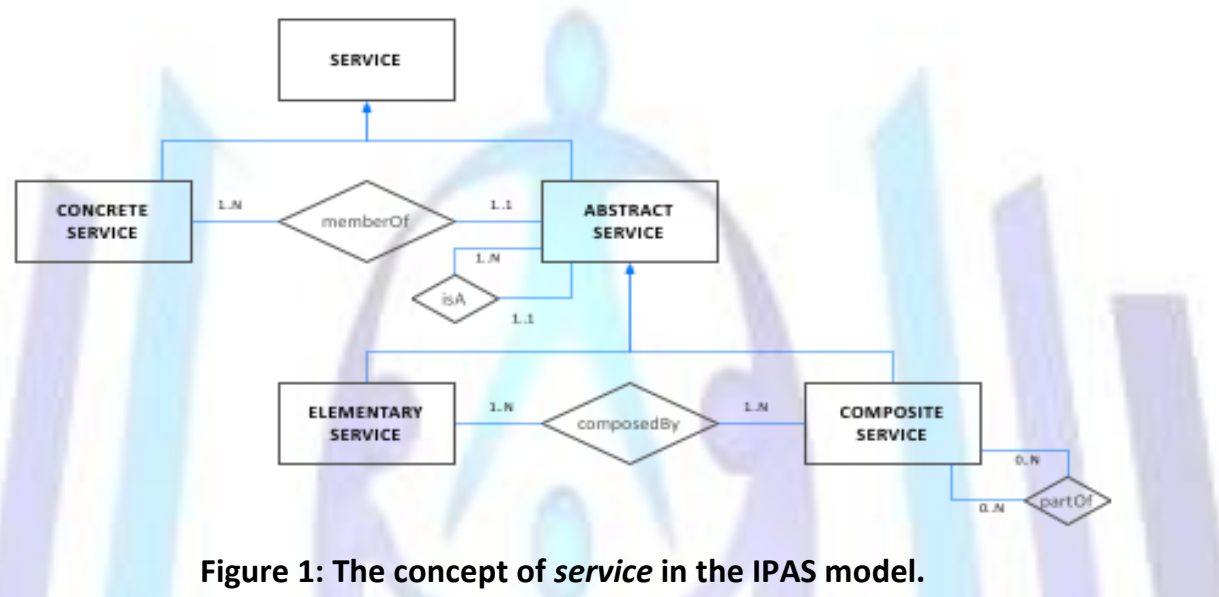

As shown in Figure 1, there are two types of service: abstract service and concrete service. The former is a service described independent from its current possible implementation (in one or more specific services), operating on one or more service management platforms. The latter is a service that operates on one or more service management platforms and it is described in terms of its concrete implementation. The abstract service identifies what service offers in terms of functionalities while the concrete service is a objectification of service in functional and non-functional terms. Figure 1 shows that the abstract services are organised hierarchically, by means of IS-A relationships, to identify broader-narrower relationships between abstract services. As an example, Payment Housing Rates Service and Payment Service have an IS-A relationship meaning that the former is a specialization of the latter.

It is possibile to distinguish the services in elementary and composite. Basically, an elementary service is a service that you have no interest to describe in terms of other services. From the point of view of PA provider, this type of service requires a single interaction with the citizen. Vice versa, a composite service is a set of elementary services, which are delivered in a coordinated way. As an example, the birth certificate release service is seen as an elementary service, since we are not interested to further represent it in terms of atomic components such as, the acquisition of the ID of the citizen, an access to the anagraphic database, and the print of the certificate. Vice versa, an example of composite service is the service that release the authorization of opening a new commercial activity; this service is composed of at least three elementary services: (a) the registration at "Chamber of Commerce"; (b) the request to the municipality in which the entrepreneur would open the commercial activity, and (c) the payment of taxes.

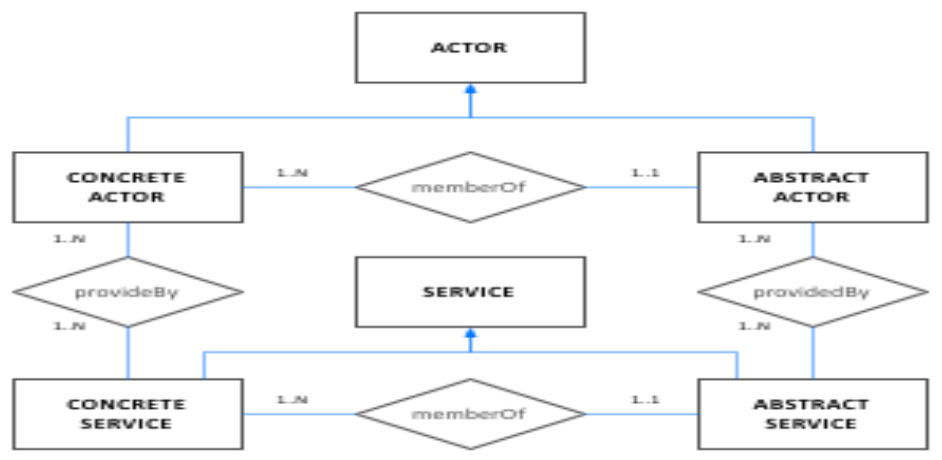

Figure 2: Characterization of actors in the IPAS model. 
The services are provided by different types of organizations and producers. As shown in Figure 2, the IPAS model maintains the distinction between abstract and concrete also for the characterization of the actor concept. For example, the abstract service of authorization for transit in the historical center of the town is provided by the abstract actor municipality; instead the authorization for transit in the historical center of Rome is provided by the concrete actor municipality of Rome.

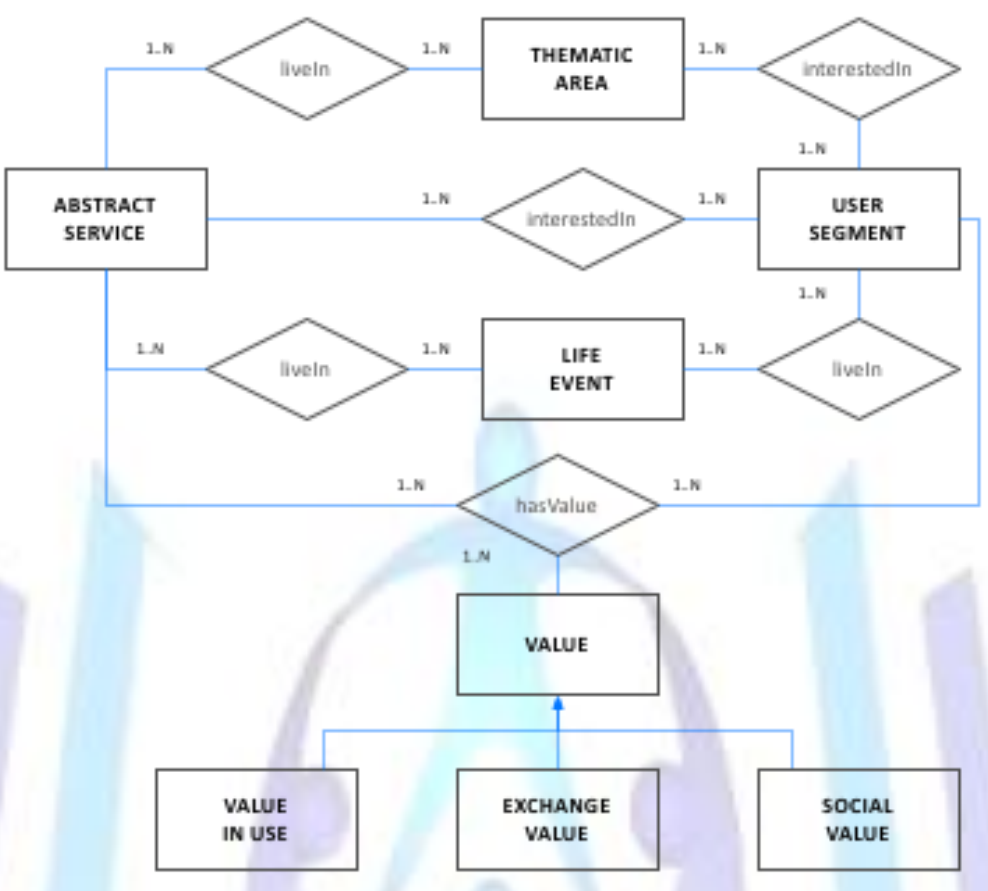

Figure 3: Characterization of abstract services in the IPAS model.

In order to better characterize the potential high number of abstract services provided by PAs, it is useful to describe them covering multiple perspectives. The results consist in offering different research paths to the citizens to be used to identify the services they need.

Figure 3 shows that the abstract service is in relation with the concept of user segment. This concept bridges with notions of marketing applied to services representing a group of individuals with uniform characteristics (e.g., age, sex, interests, etc) that are potential customers for the service.

Abstract service and user segment present relationships with the concept of life event, that is a particular situation that may occur during the life of a citizen such as having a child, acquire a citizenship and start a new business. Services are used when specific life events occur; life events can occur to specific user segments. For example, a citizen belonging to the user segment driver (i.e., citizen with a driver's licence) that changes his address (life event change of address) has to communicate the change to the department of motor vehicle using the service change of address on driver's license and vehicle registration.

Another important concept in relation with abstract service and user segment is the thematic area that is a theme or a thematic channel such as Education, Tourism, and Business that represents a possible classification for services and user segment interests. For example, a student (user segment) may be interested in services classified in the education thematic area, such as request a reductions for public transport fees.

Figure 3 also shows one of the most important concept of the IPAS model: the value of a service. The literature proposes different types of value [6][11][13] showing the wide variety of meanings of the concept. The IPAS model consents the description of three types of service value: the social value (e.g., for a Public Administration), the exchange value (for the provider) and the value in use (for the consumer).

The social value is the perceived utility of the association between the service with features taken as a stereotype, positive or negative, referring to groups or categories demographic, socio-economic or ethnic culture [11][14]. For example, the publication of news dedicated to immigrants and their problems is seen as a service with high social value.

The value in exchange is the attitude that an asset has to be exchanged with another asset; the value in exchange is a subjective characteristic of the services, as it is given to them by humans to facilitate the exchange relations. As such, it is of interest for service providers, who want to take an economic benefit from the exchange [12][13].

The value in use, at a high level of abstraction, can be defined as the trade-off between the benefits (what you get) and the sacrifices (what you give) in a market exchange [5][13]. Benefits and sacrifices are related to the user perception. 
Since also social value and value in exchange are related to user perception, the IPAS model includes a ternary relation between abstract service, value and user segment.

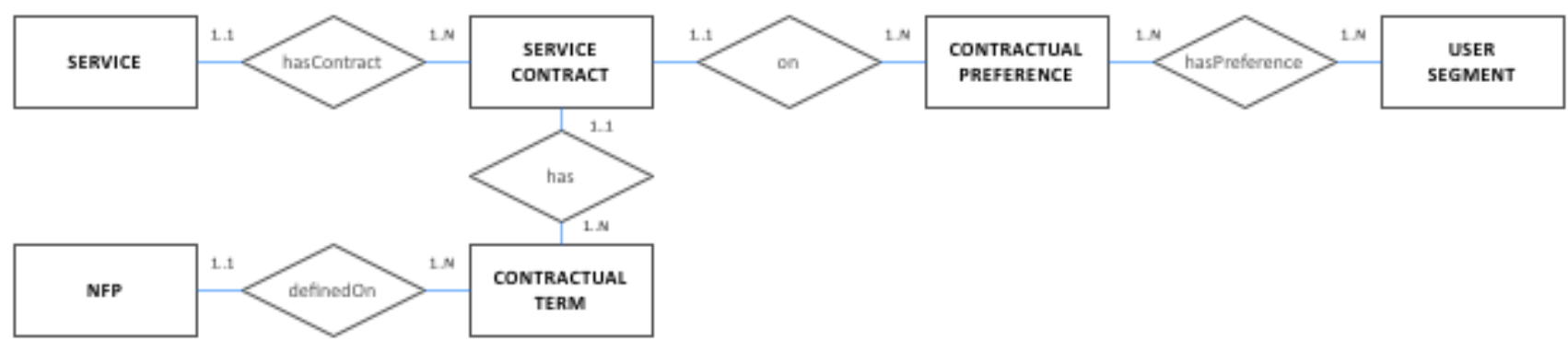

Figure 4: Characterization of service contract in the IPAS model.

According to [7], in the IPAS model a service is characterized by two types of properties: (a) functional properties and (b) non-functional properties (NFPs). The former describe what the service does for the user, in terms of the change of the state of the user that the service enables, coherently with the goals that have been expressed by the user in requirements collection. The latter specify how the service performs the functional properties.

Figure 4 focuses on how NFPs are specified in IPAS. The concept of service contract [9] is used to represent an agreement for service fruition signed by the provider and the consumer. A service contract includes one or more contractual terms described in form of conditions established on NFPs, such as quality of service (e.g., response time and availability), legal aspects (e.g., fair use and copyrights), intellectual rights (e.g., allowing or denying composition), and business aspects (including financial terms such as payment and tax). Each user segment can have contractual prefences on contractual terms to be included in the service contract.

The description of contractual terms and contractual preferences on NFPs is very important for two main tasks: (i) NFPs can represent benefits (e.g., low response time) or sacrifices (e.g., high price) for the user and strongly influence the calculation of the service value [9]; (ii) NFPs make the difference when a service is ranked among equivalents, thus making it scores higher among the recommendation set [8].

\section{A CASE STUDY}

One of the aims of the SMART project consists in the definition of a value-added service (VAS) for citizens who want to change their address of residence. In Italy, the change of address is a suitable example to show the complexity of the service ecosystem that often characterizes the e-Government domain where services to face a life event are provided by different central administrations (e.g., Ministry of Interior, Ministry of Health) and local administrations (e.g., Municipalities). The VAS must contain not only the services provided by public administrations but also services provided by private entities in order to offer to the citizens all the services they need to face the life event change of address. Moreover, the VAS aims to relieve the citizens from the analysis of the often complex dependencies between services established by the legislature, offering a set of services that are just conformed to laws and regulations.

Let us start with the list of the administrative or personal duties that have to be fulfilled when a citizen changes his address of residence: (i) notify the change of address to the Registry Office of the new municipality; (ii) choose a new doctor; (iii) report garbage tax termination for the building freed and pay the garbage tax for the new building; (iv) pay the new housing rates tax; $(v)$ change of address on the the driving license; (vi) change the contract with the gas company; (vii) change the contract with the water company; (viii) change the contract with the electricity company. In order to perform the duties, the citizen has to find and invoke eight different services.

Moreover, in addition to these services, the citizen may be interested to request some additional services, such as: (i) request facilities for the use of public transport in the new municipality; (ii) request the transfer of the telephone number into the new building; (iii) update the contract of his insurance policy.

This scenario demonstrates the necessity to inform the citizens on these services and support them in their fruition. The IPAS model goes towards this direction. Here, we show how the knowledge base ${ }^{3}$ realized using the IPAS model can be very helpful for the citizens. The knowledge base is used to discover elementary and composite services to be included into the VAS. In particular, we look for services characterized by a relationship with (i) the life event change of address and (ii) the thematic area registry office. The result is shown in Table 1:7 composed services and 37 elementary services are potential candidates for the definition of the VAS for the change of address.

The set of duties related to the change of address depends on the user segment involved, namely whether the change of address is performed by (i) a single person, (ii) multiple persons (a family), (iii) a single person that goes to live in cohabitation, (iv) multiple persons that go to live in cohabitation, (v) incoming foreign citizen, (vi) migrant Italian citizens and (vii) migrant Italian citizens with resident abroad. According to the user segment involved, groups of elementary

3 http://siti-rack.siti.disco.unimib.it:8080/ipas portal/ 
services related to the event of change of address are used jointly, resulting in seven composite services. In this case, as well as in many other administrative interactions, the citizen has the benefit to minimize the time spent to provide the same personal data to the administrations involved in the composite services.

Table 1 considers two types of services (namely,elementary and composite), and two types of conceptual relationships (namely, IS-A and PART-OF). The IS-A is used to state that a service is a specialization of a more generic service. The PART-OF is used to state that an elementary service is included into a composite service.

Table 1: Potential services to be included into the VAS for the change of address.

\begin{tabular}{|c|c|c|c|c|c|c|c|c|c|}
\hline & & & & & & & & & \\
\hline & & $\begin{array}{l}\text { Change of } \\
\text { Address }\end{array}$ & $\begin{array}{l}\text { Change of } \\
\text { Address } \\
\text { (single) }\end{array}$ & $\begin{array}{l}\text { Change of } \\
\text { Address } \\
\text { (multiple) }\end{array}$ & $\begin{array}{l}\text { Change of } \\
\text { Address } \\
\text { (single } \\
\text { cohabit.) } \\
\end{array}$ & $\begin{array}{l}\text { Change of } \\
\text { Address } \\
\text { (multiple } \\
\text { cohabit.) }\end{array}$ & $\begin{array}{l}\text { Change } \\
\text { of } \\
\text { Address } \\
\text { (foreign } \\
\text { citizen) }\end{array}$ & $\begin{array}{l}\text { Change } \\
\text { of } \\
\text { Address } \\
\text { (Italian } \\
\text { citizens } \\
\text { abroad) }\end{array}$ & $\begin{array}{l}\text { Change } \\
\text { of } \\
\text { Address } \\
\text { (Italian } \\
\text { citizens } \\
\text { residing } \\
\text { abroad) } \\
\end{array}$ \\
\hline \multirow{8}{*}{$\begin{array}{l}\text { Composite } \\
\text { services }\end{array}$} & Change of Address & - & & & & & & & \\
\hline & Change of Address (single) & IS-A & & & & & & & \\
\hline & Change of Address (multiple) & IS-A & & & & & & & \\
\hline & Change of Address (single cohabitation) & IS-A & & & & & & & \\
\hline & Change of Address (multiple cohabitation) & IS-A & 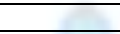 & & & & & & \\
\hline & Change of Address (foreign citizen) & IS-A & & & & & & & \\
\hline & Change of Address (Italian citizens abroad) & IS-A & & & & & & & \\
\hline & $\begin{array}{l}\text { Change of Address (Italian citizens residing } \\
\text { abroad) }\end{array}$ & IS-A & & & & & & & \\
\hline \multirow{37}{*}{$\begin{array}{l}\text { Elementary } \\
\text { services }\end{array}$} & $\begin{array}{l}\text { Entry in the the Registry of the resident } \\
\text { population of the City of destination }\end{array}$ & PART-OF & PART-OF & PART-OF & PART-OF & PART-OF & & PART-OF & \\
\hline & Issuing new voter & & PART-OF & PART-OF & PART-OF & PART-OF & & PART-OF & \\
\hline & Choice of doctor & 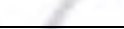 & PART-OF & PART-OF & PART-OF & PART-OF & PART-OF & PART-OF & \\
\hline & Correspondence management & & PART-OF & PART-OF & PART-OF & PART-OF & & PART-OF & \\
\hline & $\begin{array}{l}\text { Progress status information of the practices } \\
\text { for the change of residency }\end{array}$ & & PART-OF & PART-OF & PART-OF & PART-OF & & PART-OF & \\
\hline & Facilities for the use of public transport & & PART-OF & PART-OF & & & & & \\
\hline & $\begin{array}{l}\text { Transfer the water network user to a new } \\
\text { address }\end{array}$ & & PART-OF & PART-OF & & & & & \\
\hline & $\begin{array}{l}\text { Transfer the electricity network user to a new } \\
\text { address }\end{array}$ & & PART-OF & PART-OF & & & & & \\
\hline & $\begin{array}{l}\text { Transfer the gas network user to a new } \\
\text { address }\end{array}$ & & PART-OF & PART-OF & & & & & \\
\hline & Transfer telephone users to new address & 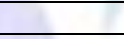 & PART-OF & PART-OF & PART-OF & PART-OF & & & \\
\hline & $\begin{array}{l}\text { Report Garbage Tax (Tarsu) termination for } \\
\text { the buiding freed }\end{array}$ & & PART-OF & PART-OF & & & & PART-OF & \\
\hline & $\begin{array}{l}\text { Report Garbage Tax (Tarsu) - new tenant of } \\
\text { a building }\end{array}$ & & PART-OF & PART-OF & & & & PART-OF & \\
\hline & Connection to the water network & & PART-OF & PART-OF & & & & PART-OF & \\
\hline & Connection to the electricity network & & PART-OF & PART-OF & & & & PART-OF & \\
\hline & Gas connection & & PART-OF & PART-OF & & & & PART-OF & \\
\hline & Connection to the telephone network & & PART-OF & PART-OF & PART-OF & PART-OF & & PART-OF & \\
\hline & Payment of local taxes & & PART-OF & PART-OF & & 2 & & PART-OF & \\
\hline & Payment Housing Rates (IMU) & 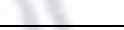 & PART-OF & PART-OF & & & & PART-OF & \\
\hline & Driveway easement & & PART-OF & PART-OF & PART-OF & PART-OF & PART-OF & PART-OF & \\
\hline & $\begin{array}{l}\text { Change of address on driver's license and } \\
\text { vehicle registration }\end{array}$ & & PART-OF & PART-OF & PART-OF & PART-OF & & PART-OF & \\
\hline & Calculating car tax & 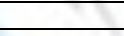 & PART-OF & PART-OF & PART-OF & PART-OF & & PART-OF & \\
\hline & $\begin{array}{l}\text { Release authorization to the movement and } \\
\text { parking in the city }\end{array}$ & & PART-OF & PART-OF & PART-OF & PART-OF & & PART-OF & \\
\hline & Release parking area reserved for disabled & & PART-OF & PART-OF & & & & & \\
\hline & $\begin{array}{l}\text { Transfer subscription RAI (National } \\
\text { Broadcasting Tax) }\end{array}$ & & PART-OF & PART-OF & PART-OF & PART-OF & & PART-OF & \\
\hline & Update your Address at the bank & & PART-OF & PART-OF & PART-OF & PART-OF & & PART-OF & \\
\hline & Updating insurance policies & & & PART-OF & & PART-OF & & & \\
\hline & Choosing kindergarten & 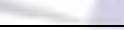 & & PART-OF & & PART-OF & & & \\
\hline & Release clearance for transfer of schools & & & & & & PART-OF & & \\
\hline & $\begin{array}{l}\text { Cancellation of the user in Registry of Italians } \\
\text { Abroad (AIRE) }\end{array}$ & & & & & & & PART-OF & \\
\hline & $\begin{array}{l}\text { Change request data enrolled in the Registry } \\
\text { of Italians Abroad (AIRE) }\end{array}$ & & & & & & & & PART-OF \\
\hline & Release of the regional card of services & & PART-OF & PART-OF & PART-OF & PART-OF & & PART-OF & \\
\hline & $\begin{array}{l}\text { Notice of change of residency (Inland } \\
\text { Revenue) }\end{array}$ & & PART-OF & PART-OF & PART-OF & PART-OF & PART-OF & PART-OF & \\
\hline & $\begin{array}{l}\text { Notice of change of residency (Social } \\
\text { Security) }\end{array}$ & & PART-OF & PART-OF & PART-OF & PART-OF & PART-OF & PART-OF & \\
\hline & Notice of change of residency to the police & & PART-OF & PART-OF & PART-OF & PART-OF & & PART-OF & \\
\hline & $\begin{array}{l}\text { Communication renewal residency to the } \\
\text { City }\end{array}$ & & PART-OF & PART-OF & PART-OF & PART-OF & & PART-OF & \\
\hline & $\begin{array}{l}\text { Cancellation in the Registry of the resident } \\
\text { population of the City of origin }\end{array}$ & PART-OF & PART-OF & PART-OF & PART-OF & PART-OF & PART-OF & PART-OF & PART-OF \\
\hline & Release of certificate of residency & PART-OF & PART-OF & PART-OF & PART-OF & PART-OF & PART-OF & PART-OF & PART-OF \\
\hline
\end{tabular}

In the first rows of Table 1, there are seven IS-A relationships defined among specific types of change of address (e.g., change of address (single)) and the generic change of address service. This generic service is characterized by three PART-OF relationships stating that it is composed by three elementary services named (i) entry in the the registry of the resident population of the city of destination, (ii) cancellation in the registry of the resident population of the city of origin and (iii) release of certificate of residency. 
This means that a citizen interested in a change of address for a single person should be potentially interested to the three elementary services inherited by Change of Address, and other thirty elementary services presenting relationship with the life event change of address and the thematic area registry office. This set of 33 services is the set of all services that a single person may need when he would change his address, but which services should be part of the VAS for a specific citizen? The possibility to analyze the relationships between each service and the user segment allows the definition of personalized VAS avoiding information overload and offering only services of interest for the citizen.

By mean of a short questionnaire, we can gather important information on the citizen and proceed with his association to one (or more) user segment. For example, let us consider that from the questionnaire compiled by the citizen we extract the following information: (i) he is Italian, (ii) he is a universitary student, (iii) he is not married, (iv) he doesn't have children, (v) he has a driver's license, (vi) he has a car, (vii) he is the owner of the new house, (viii) he has a bank account and (ix) he doesn't have an insurance policy. This information allows us to classify the citizen as: (i) Italian, (ii) student, (iii) unmarried, (iv) driver, (v) car owner and (vi) bank account holder.

Using the relationships between services and user segments defined in the IPAS model, we can personalized the VAS as shown in Table 2.

Table 2: Services included into the VAS for the change of address.

\begin{tabular}{|l|l|}
\hline 1 & Entry in the the Registry of the resident population of the City of destination \\
\hline 2 & Choice of doctor \\
\hline 3 & Connection to the water network \\
\hline 4 & Connection to the electricity network \\
\hline 5 & Gas connection \\
\hline 6 & Connection to the telephone network \\
\hline 7 & Report Garbage Tax (Tarsu) - new tenant of a building \\
\hline 8 & Payment of local taxes \\
\hline 9 & Payment Housing Rates (IMU) \\
\hline 10 & Change of address on driver's license and vehicle registration \\
\hline 11 & Calculating car tax \\
\hline 12 & Release authorization to the movement and parking in the city \\
\hline 13 & Update your Address at the bank \\
\hline 14 & Cancellation in the Registry of the resident population of the City of origin \\
\hline
\end{tabular}

\section{CONCLUSIONS AND FUTURE WORKS}

The Italian Public Administration (PA) consists in a wide set of local authorities providing services to citizens, each with its own administrative autonomy. Actually, it often happens that Italian citizens have difficulties in discovering and using services that they need in the course of their lifes. In this paper, we have presented a new version of the Italian Public Administration Service (IPAS) model [3] defined to support the definition of value-added services that simplify the interaction between Italian citizens and the PA. The case study on change of address has demonstrated the support given by the IPAS model in the definition and personalization of VAS.

In future work we will extend the IPAS model in order to better support the modeling of functional properties of services. The characterization of services through the functional specification permits a more accurate identification of services that satisfy the implicit and explicit needs of the citizens. Moreover, we will test the IPAS model into new case studies (e.g., a new VAS for citizen that would open a new commercial activity) within the SMART project.

\section{ACKNOWLEDGMENTS}

The work presented in this paper has been partially supported by the Italian PON project PON01_00861 SMART (Services and Meta-services for smART eGovernment).

\section{REFERENCES}

[1] G. Viscusi, C. Batini, and M. Mecella: Information Systems for eGovernment: A Quality-of-Service Perspective. Springer, 2010.

[2] C. Batini, G. Viscusi, and D. Cherubini: GovQual: A quality driven methodology for E-Government project planning. Government Information Quarterly, vol. 26, no. 1, pp. 106-117, 2009.

[3] M. Palmonari, G. Viscusi, and C. Batini: A semantic repository approach to improve the government to business relationship. Data Knowl. Eng. 65(3): 485-511 (2008).

[4] J. Gordijn, E. Yu, and B. van der Raadt: E-service design using $i^{\star}$ and e3Value modeling. Software, IEEE, vol. 23, no. 3, pp. 26-33, 2006.

[5] C. Grönroos: Service Management and Marketing. Managing the Moments of Truth in Service Competition Lexington Books, 1990.

[6] V. A. Zeithaml. Consumer perceptions of price, quality, and value: A means-end model and synthesis of evidence. Journal of Marketing, vol. 52, no. 3, pp. pp. 2-22, 1988.

[7] F. De Paoli, M. Palmonari, M. Comerio, and A. Maurino. A Meta-Model for Non-Functional Property Descriptions of Web Services. In proc. of ICWS (IEEE International Conference on Web Services) 2008, pp. 393-400.

[8] M. Palmonari, M. Comerio, and F. De Paoli. Effective and Flexible NFP-based Ranking of Web Services. In proc. of ICSOC (International Conference on Service Oriented Computing) 2009, pp. 546-560. 
[9] M. Comerio. Value-based Service Contract Selection. In proc. of SCC (International Conference on Service Computing) 2013.

[10] M. Comerio, S. Grega, M. Palmonari, and G. Viscusi. Alignment of Service Science and Service Oriented Computing: A Unified Interpretative Approach to Service Design and Planning. In Information Systems: Crossroads for Organization, Management, Accounting and Engineering, M. De Marco, D. Te'eni, V. Albano, and S. Za, Eds. Physica-Verlag HD, 2012, pp. 519-526. ISBN: 978-3-7908-2788-0.

[11] A. Sen. Rationality and Freedom. Harvard University, Cambridge, Mass, 2002.

[12] J. Ramsay. The real meaning of value in trading relationships. International Journal of Operations \& Production Management, 2005, Vol. 25, No. 6, pp. 549-565.

[13] S. L. Vargo, M. A. Akaka. Service-Dominant Logic as a Foundation for Service Science: Clarifications. Science, vol. 1, no. 1, pp. 32-41, 2009.

[14] I. Robeyns, The Capability Approach: a theoretical survey. Journal of Human Development, vol. 6, no. 1, pp. 93-117, 2005.

\section{Authors' biography with Photo}

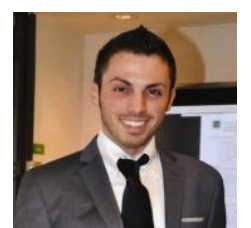

Marco Castelli is currently a research assistant at the Department of Informatics, Systems and Communication (DISCo) of the University of Milan Bicocca. His research interests cover Information Value and Service Value. In past he played some professional experience including two years in the IT Department of a large company of the manufacturing sector.

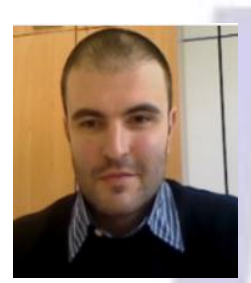

Marco Comerio is currently post-doc research fellow at the Department of Informatics, Systems and Communication (DISCo) of the University of Milan Bicocca: the research title is "Web service contracts: specification, selection and composition". The main results of the research activity are: (i) the definition of the Policy-Centered Metamodel (PCM), a meta-model for the description of expressive contractual terms to be included in service contracts and (ii) design and implementation of the Policy Matchmaker and Ranker (PoliMaR), a tool allowing for an effective and flexible service contract selection that can be used to improve the traditional service discovery process. He has published more than 40 referred papers in books, conference proceedings, and journals.

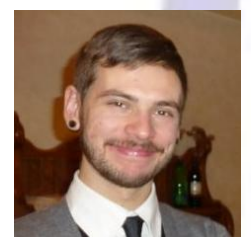

Marco Cremaschi is currently a research assistant at the Department of Informatics, Systems and Communication (DISCo) of the University of Milan Bicocca. His research interests include the definition of models for the description of PA services and the design and implementation of tools for the management of services. He has worked in several research projects related to the agri-food domain and e-government domain. 